\section{B.D.H. Products}

WE have received from the British Drug Houses, Ltd., London, N.1., copies of their catalogues of fine chemical products and micro-analytical reagents and organic reagents for 'spot' tests. The standards of purity adopted for ehemical products are described in the B.D.H. book of A. R. Standards and those for pharmaceutical preparations in the book of P.P.P. (pure for pharmaceutical purposes) Standards. In the case of the latter, other considerations as well as purity must be taken into account, for example, ease of weighing for dispensing, and ready solubility with the formation of a clear bright solution. Low limits for lead and arsenic are defined, being in the case of most substances only a few parts ( 1 to 5 ) in a million. Other metallic impurities may not be physiologically harmful, but may cause precipitation, coloration, or some other reaction and so create difficulties in dispensing : their limits must therefore be fixed as well. The catalogues of fine chemicals run to nearly 150 pages and include lists of standard reagents, indicators, microscopic stains, and dyes. The same firm has also issued recently revised editions of booklets describing their vitamin $A$ and vitamin $D$ preparations, avoleum, radiostol, radiostoleum, and radio-malt. Advance in our knowledge in the vitamin field has been so rapid that frequent revision of brief summaries of this work is required. The activities of the products are controlled by physiological tests and standardised in terms of the international standards wherever such standards are availabie.

\section{Treatment of L eprosy}

Derivatives of chaulmoogra and hydnocarpus oils now have an established position in the treatment of leprosy. The active constituents are certain fatty acids, which are usually administered as their soluble sodium salts or as the ethyl esters. A mixture of esters of the acids of the chaulmoogric series with 0.5 per cent iodine has been recently recommended for the intradermal treatment of the superficial lesions of the disease : the addition of the iodine reduces the irritating properties of the ethyl esters. The intradermal method is relatively free from general and local reactions : rapid resolution of the raised macules, infiltrations, and nodules is reported when small amounts of the solution of esters and iodine are injected into the skin around them. Messrs. Burroughs, Wellcome and Co., London, have issued a solution of these esters with 0.5 per cent iodine, suitable for intradermal and intramuscular administration, under the name "Iodised Moogrol". It is recommended that 5 c.c. be given at weekly intervals : the intradermal injection should be $0 \cdot 1$ c.c. at each point. Intradermal administration should be combined with intramuscular, part of the dose being given by each route.

\section{Oceanography of the Baffin Bay Region}

The United States Coastguard in 1928 sent an expedition in the ship Marion into Davis Strait and Baffin Bay to carry out scientific investigations connected with the international ice patrol, particularly in regard to ocean currents, ocean depths, and ice conditions in the region north of that usually covered by the ice-patrol vessels each spring and summer. The ship followed a zigzag track northward from the Gulf of St. Lawrence to and fro between Labrador, Greenland, and Baffin Island. An account of the expedition and its results are being issued as the U.S. Coastguard Bulletin 19, published in three parts. Part 1 (Washington: Government Printing Office, 1932 ; pp. 81, 50 c.), just issued, contains a fascinating narrative of the cruise, illustrated by 38 well reproduced photographs; it gives also a report and discussion of the sounding work accomplished (by the echo method), and a description and discussion of the bottom samples obtained at some of the places where wire soundings were made. Part 3, published last year, dealt with the arctic ice and its drift into the North Atlantic Ocean, while Part 2, to be issued shortly, will report on the oceanography of Baffin Bay and Davis Strait.

\section{Physiography of the Nile Basin}

IN recent years a great deal of information on the Nile basin, the regime of the Nile, and the control of its floods has been collected by the Irrigation and Physical Department of the Egyptian Ministry of Public Works. This has resulted in a series of valuable papers, including the volumes on the Lake Plateau Basin of the Nile published in 1925 and 1927. This work continues and is being correlated with meteorological and hydrographical work in Uganda and other parts of East Africa. The Irrigation and Physical Department has now published the first of a new series of volumes on the Nile ("The Nile Basin." H. E. Hurst and P. Phillips. Physical Dept. Paper 26. Cairo, 1931. P.T.50). It deals particularly with the topography of the Lake Plateau, Bahr-elJebal, Bahr-el-Ghazel, Sobat basin, and White Nile basin, with a full account of the meteorology of the whole basin. A feature of the book is the large number of coloured folding maps, including maps of the whole basin on a scale of 1 to $2,000,000$. There are also numerous climatic maps and many excellent illustrations. The volume concludes with a long bibliography of the Nile.

\section{Plains of Southern Alberta}

A REGION embracing such well-known names to the petroleum technologist as Calgary, Turner Valley, Bow Island, and Medicine Hat, will always preserve a certain freshness, but more because of its oil and gas industry than on account of any special geological merit. Yet the Alberta Society of Petroleum Geologists has made much lately of its stratigraphy and palæontology, and publications concerning these aspects of research have not been by any means restricted. As is often the case where a sense of vastness seems to engulf human effort, so in the Southern Plains has much of the significance of disconnected work been lost to the wider fraternity of geologists. The Donaldson Bogart Dowling Memorial Symposium on this stratigraphy (Tulsa, Oklahoma: Amer. Assoc. of Pet. Geol.; London : T. Murby and Co. 3 dollars) is not only a happy thought to the memory of a

No. 3276, VoL. 130] 